\title{
The Invisible Arp
}

\author{
David Upton \\ King's College \\ The Strand, London WC2R 2LS, UK \\ cogible@gmail.com
}

\begin{abstract}
This paper describes a conceptual generative art system built in the Cloud, which exercises a degree of autonomy in deciding when and for whom to generate art works, but bases its processes on the ideas of a dead artist. The philosopher Douglas Hofstadter claims that humans are basically just a set of patterns, instantiated in mortal cells, but capable of surviving after death. After a study of the works and writings of poet and artist Hans Arp, I have tried to identify some of the 'patterns' or rules that guided Arp's artistic practice. These have been converted into computer code, and guide the generative system, in the hope that it can produce art works as Arp might do if he was alive today (not crude copies of his one hundred year old works). Participants at EVA 2018 are invited to judge how successful this has been. To emphasise the intangibility of the patterns, the system is hosted in the Cloud, making it as near as possible non-existent, in any physical or virtual sense. What are the implications if such patterns really can persist after death?
\end{abstract}

Generative art. Cloud. Immortality. Patterns. Isomorphism. Dada. Poetry. Visual art. Python.

\section{INTRODUCTION}

This essay describes a generative art system, which is influenced by the strategies and techniques of an artist, Hans Arp, who died in 1966.

It began as an attempt to create an autonomous generative art machine, but then grew to include an attempt to capture the 'patterns' in the head of a dead artist (Hans Arp) and reproduce them in computer code.

A study of Arp's work revealed patterns at several levels. This allowed me to choose 'inspirations', from modern news sources that would have captured his imagination, and then to identify some of his strategies, such as 'simplification' and 'randomness'. Some ways that Arp implemented these strategies in his poems and images can be identified, and I have attempted to do so and to formulate them in a computer programme.

Lack of space prevents me from going into detail about the programming. This is also a 'work in progress' and its first appearance, at EVA 2018, is an experiment. Art works may be generated and emailed to conference attendees, and I look forward to receiving comments. However, it is the overall principle that matters: can we really capture some of the ways that a dead man behaved and reproduce them?

\section{AN AUTONOMOUS MACHINE?}

This work began with a challenge issued last EVA London by Jon McCormack:

If [autonomy on creative systems] is dependent on free will, then any artificially autonomous creative software would need to make the choice to make art, not be explicitly programmed to do so.

I spent some time thinking about my human decisions, and concluded that these typically have four motivations:

- My likes or dislikes. These may have unconscious motivations, but are what I mean when I say "I like chocolate but not toffee". I simply 'am' that way, and I don't expect to have to justify these feelings.

- My general mood, which depends largely on events around me. Some days I am happy and more willing to take on new things; other days I withdraw into my shell.

- My prejudices against people or groups.

- My prejudices in favour of people and groups. Possibly we are old friends, or share a liking for Italian food.

The reality of the second motivation was clearly demonstrated by a now notorious Facebook 
experiment, in which users who were 'fed' good news posted more material, and this material was more optimistic, than those who were not (Kramer et al., 2013).

The third and fourth depend largely on my personal circumstances: for example, a Belfast Catholic, and a Rohingya living in Myanmar, are brought up amidst temptations towards entirely different sets of prejudices, for and against people and groups.

Only the first option is arguably a decision ' $I$ ' make, and even then there may be personal historical reasons (I don't like toffee because I once lost a filling, for example) or deep-seated psychological reasons.

To simulate this process, my generative art machine is regularly fed a list of email addresses, and has to decide whether to generate an email to each one of these. It does so by:

- "Likes or dislikes": a random number generator, which gives it a 'like or dislike' score. This is the only completely 'autonomous decision' the machine makes: but I argue that only a small part of any human 'decision' is actually free from external pressures.

- "General mood" it looks at the day's news events and uses a simple sentiment analysis programme to decide whether it is a 'happy' day or not.

- "Prejudices against people or groups". I did not want to attempt to build a realistic set of prejudices into the model! Besides, all the machine knows about you is your email address. So, to simulate racism, sexism, etc., it counts the characters in that address. It looks to see if today's date is an odd or an even number. If today is odd and you have an even number of characters, it is prejudiced against you, and vice versa.

- "Prejudices in favour of people and groups". It looks again at the first letter of your email address and divides the alphabet into five groups (a-e, f-j, etc.). It selects one of these groups; if your first letter is in that group, it is prejudiced in your favour.

- It adds the scores, and responds if they surpass a set threshold.

This leaves the machine deciding, with I think as much autonomy as a human, whether to send you an email or not. I can alter the response threshold, making it send out more or fewer on each run, but that's all. Of course the machine does not have intentionality - it has no idea what it is doing - but it has autonomy over this decision, and this is more than just a random number generation

\section{THE 'SOUL' OF AN ARTIST?}

The machine may have some autonomy, but it is still a product of my mind and my perceptions. How could I get round this?

The more I thought about 'intentionality', the more I thought of the words of philosopher Douglas Hofstadter:

\section{Can you ever have absorbed so much of [another person] that when that primary brain perishes, you can feel that that person did not totally perish from the earth, because they (or at least a significant fraction of them) are still instantiate in your brain... The cells inside a brain are not the bearers of its consciousness, the bearers of consciousness are patterns... and patterns can be copied from one medium to another, even between radically different media (Hofstadter 2007, p.257).}

Hofstadter's wife died, tragically young, while he was writing that book, and he recounts movingly how he saw things through her eyes, how he knew how she would have responded to situations and what they would have meant to her, because he had to some extent internalised her patterns (I will use Hofstadter's word 'patterns' throughout, to avoid arguments about whether these are the 'soul' or the 'mind', or any other value-laden definition).

I began to wonder if a generative art machine could re-instantiate of the 'patterns' of a great artist. This is a science-fiction dream, where two people sit with what look like colanders on their heads, and with much flashing and buzzing, the brain of one is transferred to the body of the other.

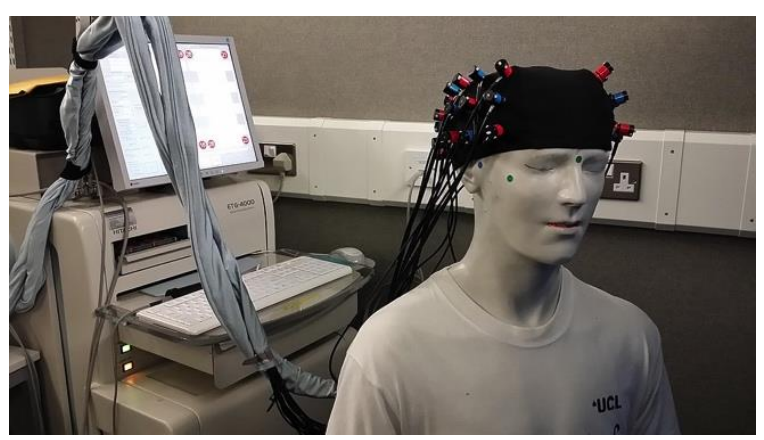

Figure 1: Reading brain patterns

Of course, since I have no way of knowing what is inside your head, the only way to actually demonstrate such a transmission would be to see if the recipient of the brain patterns reacted in a similar way to the originator, when faced with a task.

I therefore experimented to find out if I could study an artist, and recreate his 'patterns' in such a way 
that a generative art machine could be tasked to generate similar works.

Please note, I am not talking about writing a system that simply copies existing art works and pastiches them. This has been done often, and for some artists, such as Mondrian, it is very easy to do. (Google Creative Lab 2018). Instead, the idea is to produce a machine that would react today as its subject might have done, had he still been alive, and show this reaction in an artwork.

It is not a completely autonomous machine: but it is controlled - not by me - but by patterns based on a long-dead artist.

The artist selected was Hans (Jean) Arp (1886 1966), since he was one of the first 'generative' artists, using the laws of chance to shape his pictures, for example by dropping coloured paper shapes on his canvas, and fixing them where they fell. Since Arp changed his styles and world-view during his life, I have focussed on his early Dada period, and immediately afterwards.

\section{THREE LEVELS OF PATTERNS}

Arp was above all an original thinker. He worked in many different media: drawings and paintings, sculptures, collages, poems, interventions, etc. As part of the Dada group, he was highly unconventional; most contemporaries thought him eccentric, or worse. He constantly tried new media and new forms.

Luckily, Arp, and those close to him, have left three levels of evidence about his patterns.

\subsection{Top level}

At the top level, Arp was angry and sick about the world, and sought to create a purer, simpler, more peaceful world, free from the noise and misleading spectacle of the nineteenth century establishment:

Disgusted by the slaughter of the World War in 1914, we dedicated ourselves to the fine arts in Zurich. While in the distance the thunder of the cannons rumbled, we sang, painted, glued, wrote with all our strength. We were looking for an elemental art which would heal people of the madness of the times and a new order which would restore the balance between heaven and hell (Arp n.d.).

At the same time he was a dreamer, who thought that art might find a deeper level of reality. Rimbach (1963) argues that Arp transcended the 'antiintellectual' tendencies of Zurich Dada and 'centred his whole life-work around a philosophical problem'. Arp said: "Dada was more than a kettle-drum, a big noise, and a joke. Among the Dadaists there were... believers and... great dreamers". Clearly Arp included himself amongst them (Rimbach 1963, p.159). Dada was a tool:

Dada aimed to destroy the reasonable deceptions of man and recover the natural and unreasonable order. Dada wanted to replace the logical nonsense of the men of today by the illogically senseless (Arp 1948).

In the original French the last sentence is more elegant and more meaningful: 'Dada voulait remplacer le non-sens logique des homes d'aujourd'hui par le sans-sens illogique' - in other words this is not nonsense but 'without sense'. 'Nonsense' implies that sense exists; Arp believed that it did not, except as a human self-deception.

His dream was that of transcending or losing the self and achieving unity with creation, whether this be materials and shapes, or higher forces. Rimbach (1963 p 154) quotes Arp saying 'Never would the eye have perceived the sun if it had not first taken the form of the sun'.

This level was simulated by analysing current news headlines, prioritising those that might have interested Arp, or provided him with starting points to express his views, and using them to 'inspire' a creative act. Sadly, there is enough madness in the world today to make such headlines easy to find.

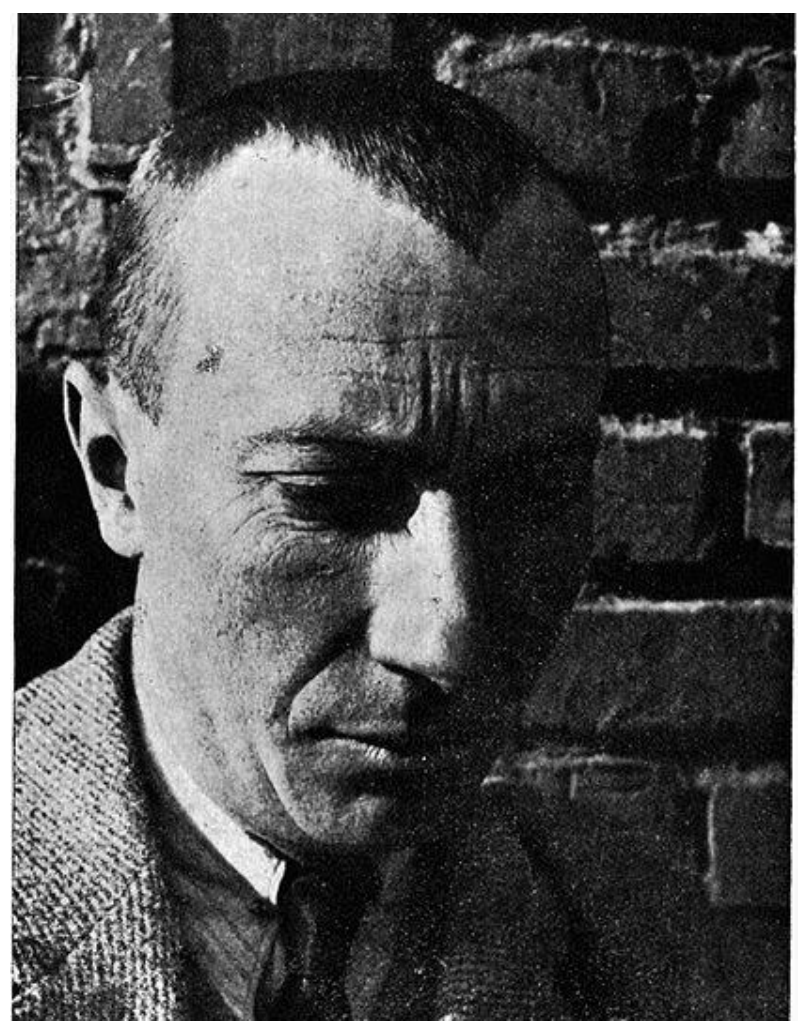

Figure 2: Hans Arp, 1886-1966 


\subsection{Strategic level}

The second level of evidence concerns the artistic strategies Arp used to express his views. The first was to simplify images, to reduce them to a kind of pure, 'original' level. Hugo Ball records that Arp:

[W]ould like to see things more ordered and less capricious, less brimming with colour and poetry... sentiment must go, and so must analysis when it occurs only on the canvas itself... He is in favour of the use of unequivocal (preferably printed) colours... [and] mechanical exactness... he is concerned not so much with richness as with simplification... he wants to purify the imagination and to concentrate in opening up not so much its store of images, but what those images are made of (Ball 1996, p.53).

He adopted chance as a second key strategy.

The law of chance, which embraces all laws and is unfathomable like the first cause from which all life arises, can only be experienced through complete devotion to the unconscious (Arp 1948, p.77).

This was coupled with constant experimentation:

He created images out of materials that until then were scarcely considered customary, such as paper, cloth, wood, instead of paint. He employed unusual techniques or invented new ones: gluing, tearing, cutting up. He rejected the traditional contents of images by simplifying drawings of twigs, roots, grasses, or stones into "dynamic ovals" or by creating geometric constellations from the very start out of planes and colours. The artistic aim of this work, which he repeatedly stressed in retrospective commentary, was purity, impersonality, simplicity. The work of art was no longer to have any relationship with a depictable external reality and its objects.

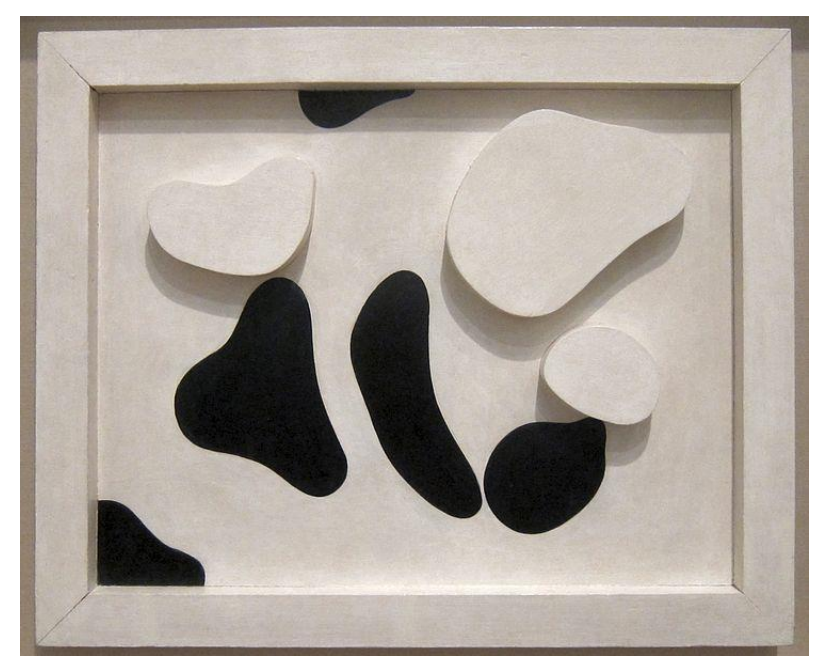

Figure 3: Constellation according to the laws of chance, Arp c. 1930.
Arp is perhaps best known for images like the one shown in Figure 3.

Which strategies the system uses depend on the contents and salience for Arp of the selected 'inspiration' - news stories or images. The system tries to assign a mix of strategies to each 'inspiration', based on what is known about Arp. The system also rates the mood of the day, again based on sentiment analysis of news media, which also influences its choice of strategies.

\subsection{Working level}

At the third, working, level, Arp has left some indications of the processes he used to instantiate these strategies.

For simplicity, I have chosen to focus on just three types of work:

- His poems, which he called 'Arpades' or sometimes 'Fatagagas'.

- Images based on simplification.

- Images based on random alignment.

The system decides which of these types to generate, based partly on content and partly on external factors.

\subsubsection{Poetry}

With regards the poetry, Arp wrote in both German and French (calling himself Hans Arp in German and Jean Arp in French). He was an Alsatian; his mother was French and his father German. Alsace has historically been passed back and forth between French and German sovereignty, and has anyway its own dialects, similar to Swiss German. Because of Arp's aloofness from any one language, I feel it is not unrealistic to generate works in a third language, English.

It is not difficult to assemble random groups of words culled from the 'inspiration' texts. But I don't believe Arp actually did this.

As well as chance selections of words and images, described above, various commentators (e.g., Rinbach 1963) have identified the stylistic processes Arp used:

- Puns.

- Oxymorons (contradictory terms conjoined).

- Using portmanteau words, two words fused together such as 'cloud pump'.

- Deliberately using unclear handwriting, so that "so that the printer would be forced to use his imagination" (Doel n.d.). This can sometimes have the effect of producing 'puns', where the original word is clear but the new word adds a different meaning. For 
example, in an early system test, the South Africa politician 'Cyril Ramaphosa' came out as 'Cyril Gramophone'.

It seems clear that Arp used some sort of subjective judgement to 'improve' his random word patterns. For example, "Posaune ohne Mund und Loch" (trombone without mouth or hole) from his poem Opus Null is more meaningful than "hole mouth trombone without". As Gideon-Welcker says:

He subsequently conjures up a transformed world, full of ingenious and paradoxical ties between bodies and idea, an irrational world where everything is fraternally compatible with everything else (Gideon-Welcker 1948 p.121)

It is this ability to find odd 'configurations', in which things take on new relationships to each other, seeming to offer new but absurd insights, which characterises Arp's poetry, and in a different way many of his images.

As Rimbach (1963, p.162) puts it: "[w]ords are petrified metaphors whose meaning has to be liberated". Putting words in strange juxtaposition stimulates the reader to re-examine the word and to 'liberate' the new meanings.

After some experimentation, I simulated some of this human judgement by:

1. Taking current news headlines.

2. Breaking them down into Parts of Speech (POS) - i.e. nouns, verbs, etc.

3. Randomising them but keeping to set patterns - e.g. adjective, noun, verb, noun, etc.

Or else, by generating lines of new words following set POS patterns. Using words from a list of words Arp used regularly, this produces lines such as "grey bird get within chair" or "dressed stones get away tails", which again appear to have some sort of meaningful configuration behind them. This is enhanced by generating puns, oxymorons, portmanteau words, etc., from time to time.

However, I believe that many of the 'associations' we see are in fact created in the mind of the reader. As Barthes would say: "... a text's unity lies not in its origin but in its destination" (Barthes, 1968). In this sense, the author (or the generative programme) is not fully responsible for the interpretations the reader makes. This adds a further, effectively random, element to the process, which I think Arp would have liked.

\subsubsection{Images based on simplification}

Arp is best known for images in which strange but simple shapes are combined in structured ways.
Simplification is a difficult concept. Intellectually it is too vague, too mystical, to reproduce in code. Ball describes how Arp would 'simplify' images.

$\mathrm{He}$ wants to purify the imagination and concentrate on opening up not so much its store of images but what those images are made of. $\mathrm{He}$ assumes that the images of the imagination are already composites (Ball, 1996, p 53).

Visually, however, it is possible, using a Python PIL filter, which averages out values over adjacent pixels, to simplify forms back to an overall pattern.
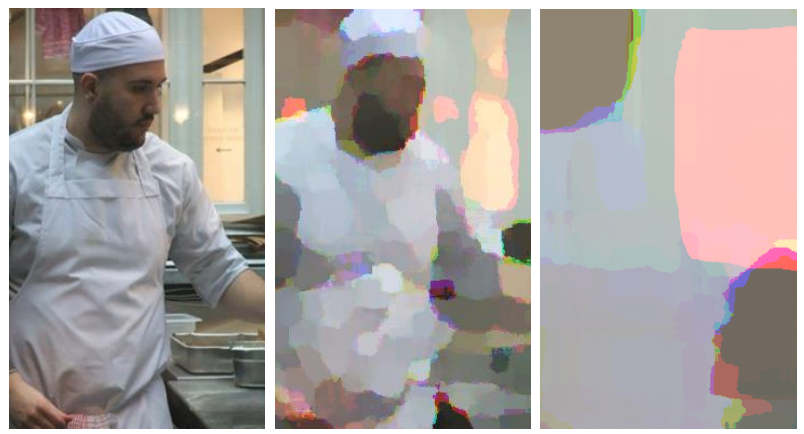

Figure 4: Chef image simplified, Covent Garden, 2018

The image of a chef shown in Figure 4 is 'simplified' until it is just a few basic shapes. In each case, the programme is simplifying the overall images in favour of what makes them up. This technique needs more work in order to achieve the hard lines that Arp preferred. It is also quite timeconsuming, and needs to be done beforehand to produce a heap of images from which the algorithm can select.

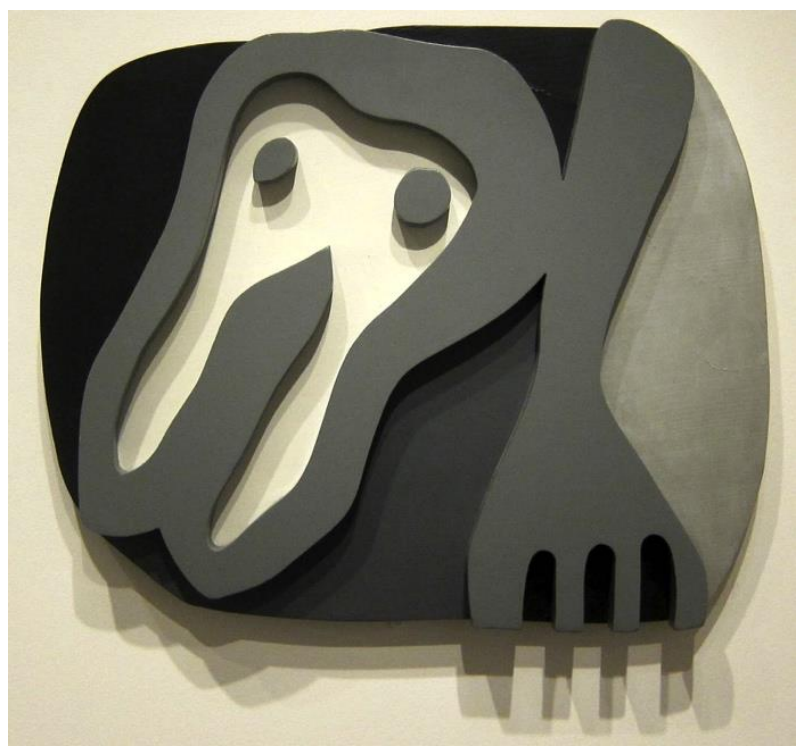

Figure 5: Arp, Shirt Front and Fork, 1922.

Just as in his poetry, Arp often produces 'configurations' in which the juxtaposed simplified objects seem to create new meanings and new 
resonances, as in the famous 'Shirt and Fork' wood image.

\subsubsection{Images based on random alignment}

Randomness, or chance, was important to Arp. He claimed that:

I continued the development of glued works by structuring them spontaneously, automatically. I called this working 'according to the law of chance.' The 'law of chance', which incorporates all laws and is as inscrutable to us as is the abyss from which all life comes, can only be experienced by surrendering completely to the unconscious. I claimed that, whoever follows this law, will create pure life (Arp 1948, p.77).

Some of his earliest works were based on this principle:

In 1915 Sophie Taueber and I made in painting, embroidery and collage, the first works derived from these simplest forms...since the disposition of planes, and the proportions and colours of the planes, seemed to depend purely on chance, I declared that these works, like Nature, were ordered according to the law of chance (Arp 1948, p.40).

The images used were to be simplified, also 'impersonal and austere', and:

A love of the circle and the cube, of sharply intersected lines. He is in favour of the use of unequivocal (preferably printed) colours (bright paper and fabric); and he is especially in favour of the inclusion of mechanical exactness (Ball 1996 p.53).

Generating circles and squares at random is easily possibly using the Python PIL library; they come with mechanical exactness, as well! However, Arp was no Mondrian, and no Malevich: his images are not quite as brutally geometric as he seemed to think. He wrote:

I remember a discussion with Mondrian in which he distinguished between art and nature, saying that art is artificial and nature natural. I do not share his opinion... art is of natural origin and is sublimated and spiritualised through the sublimation of man (Arp 1948 p.51).

I compromised by setting the system to combine simplification, randomness, and some collage techniques to produce and manipulate images.

\section{AN EXPERIMENT}

During the EVA London 2018 conference, the system will be run. Conference attendees will be asked to give their email addressees. These will be fed to the system, which will decide when and to whom to respond. At the end of the EVA conference the system will delete the email addresses, and turn itself off.

During the conference, participants may therefore receive emails attaching 'art works' as Arp might have made them. It is not intended that they should be copies or pastiches of works by Arp, but rather that they will have some degree of artistic integrity, and be in line with the 'patterns' Arp used a hundred years ago.

\section{A NON-EXISTENT SYSTEM?}

This experiment is to see if 'patterns' can be totally abstracted from the human brain cells, which once held them, and transferred to another medium.

In an attempt to make the experiment as thorough as possible, the system is housed in the Amazon EC2 cloud. This means that you cannot point to a single physical server and say that it resides in the memory of that machine. Cloud systems store only 'templates' (or patterns), and use these to 'spin up' an actual server programme on a physical computer when the system is called over the Internet. In this sense, the new 'brain', which is holding Arp's patterns, only exists for a few moments, in a physical machine chosen by an unpredictable algorithm, dependent on system loading and other external conditions.

Perhaps this emphasises Douglas Hofstadter's argument that it is the patterns that matter, and not the physical or virtual system - brain or computer that holds them.

\section{CONCLUSIONS}

This essay describes an attempt to capture the artistic patterns of an individual artist, to reproduce them, and then to undertake a preliminary test of their reproducibility. EVA London 2018 will be the first 'live' test of the machine, and I am aware that it has many failings.

Users may feel that my understanding of Arp's 'patterns' is inadequate. They may also feel that the machine's new versions of Arp are unconvincing because I have at least partly failed to capture Arp's 'patterns' in code.

Both these are probably valid criticisms: but the first powered flight lasted for only 11 seconds, and look where air travel is today.

I have tried to establish that we can identify certain human patterns, transmit them, and re-instantiate them in a machine - and that this machine can produce recognisable effects. 
If you accept that this work demonstrates that the principle can be achieved, however feebly, then to what feats of pattern transference can we look forward over the next hundred years?

Neuroscience, more comprehensive behavioural data gathering, and more sophisticated interpretation, will provide future programmers with much more information about today and tomorrow's artists, and their artistic practices. Perhaps future artists will deliberately identify and store their own patterns, in order to achieve a degree of 'immortality'?

Perhaps, if this principle can be applied to artists, it can also be applied to others who produce recognisable work functions and methods that can be re-instantiated in a future context: scientists, perhaps, or philosophers?

\section{REFERENCES}

Arp, H. (1948) On My Way. Trans. R. Manheim. Wittenborn, Schulz, New York.

Arp, H. (n.d.) Dadaland. In: Documents Dada (2010). http://dadasurr.blogspot.com/2010/01/hansarp.html (retrieved 7 March 2018).
Ball, H. (1996) Flight Out of Time. Translated by J. Elderfield. University of California Press, Berkeley.

Barthes, R. (1977) Image-Music-Text. Hill and Wang, New York. pp.142-148.

http://neamathisi.com/literacies/chapter-7-literaciesas-multimodal-designs-for-meaning/roland-bartheson-the-death-of-the-author (retrieved 19 March 2018).

Doel, R. (n.d.) Hans Arp and Zurich Dada. https://reinhard-doehl.de/arp zurichdada.htm (retrieved 18 March 2018).

Gideon-Welcker, C. (1948) Arp essay. In: On My Way, Wittenborn, Schulz, New York, pp.119-124.

Google Creative Lab (2018) Make Your Own Mondrian. https://googlecreativelab.github.io/coderprojects/projects/mondrian/ (retrieved 22 February 2018).

Hofstadter, D. (2007) I am a Strange Loop. Basic Books, New York.

McCormack, J. (2017) Working with Generative systems. EVA London 2017: Electronic Visualisation and the Arts. BCS, Electronic Workshops in Computing, pp.213-218.

Rimbach, G. (1963) Sense and Nonsense in the Poetry of Hans Arp. The German Quarterly, 36(2), pp.152-163, March. 